\title{
ITERATIVE APPROXIMATION OF FIXED POINTS FOR $\phi$-HEMICONTRACTIVE OPERATORS IN BANACH SPACES
}

\author{
Zeqing Liu, Zhefu An, Yanjuan Li and Shin Min Kang
}

\begin{abstract}
Suppose that $X$ is a real Banach space, $K$ is a nonempty closed convex subset of $X$ and $T: K \rightarrow K$ is a uniformly continuous $\phi$-hemicontractive operator or a Lipschitz $\phi$-hemicontractive operator. In this paper we prove that under certain conditions the three-step iteration methods with errors converge strongly to the unique fixed point of $T$. Our results extend the corresponding results of Chang [1], Chang et al. [2], Chidume [3]-[7], Chidume and Osilike [9], Deng [10], Liu and Kang [13], [14], Osilike [15], [16] and Tan and $\mathrm{Xu}[17]$.
\end{abstract}

\section{Introduction}

For a real Banach space, we denote by $J$ the normalized duality mapping from $X$ into $2^{X^{*}}$ given by

$$
J(x)=\left\{f \in X^{*}:\langle x, f\rangle=\|x\|^{2}=\|f\|^{2}\right\}, \quad x \in X,
$$

where $X^{*}$ denotes the dual space of $X$ and $\langle\cdot, \cdot\rangle$ denotes the generalized duality pairing between $X$ and $X^{*}$. In the sequel, $I$ denotes the identity operator on $X$. An operator $T$ with domain $D(T)$ and range $R(T)$ in $X$ is called strongly pseudocontractive if there exists a constant $t>1$ such that for any given $x, y \in D(T)$ there exists $j(x-y) \in J(x-y)$ satisfying

$$
\langle T x-T y, j(x-y)\rangle \leq t^{-1}\|x-y\|^{2} .
$$

Received February 10, 2003.

2000 Mathematics Subject Classification: 47H05, 47H06, 47H10, 47H14.

Key words and phrases: $\phi$-pseudocontractive operator, $\phi$-hemicontractive operators, the three-step iteration method with errors, fixed point, Banach spaces.

This work was supported by Korea Research Foundation Grant (KRF-2000-015DP0013). 
$T$ is called $\phi$-strongly pseudocontractive if there exists a strictly increasing function $\phi:[0, \infty) \rightarrow[0, \infty)$ with $\phi(0)=0$ such that for any given $x, y \in D(T)$ there exists $j(x-y) \in J(x-y)$ satisfying

$$
\langle T x-T y, j(x-y)\rangle \leq\|x-y\|^{2}-\phi(\|x-y\|)\|x-y\| .
$$

$T$ is called $\phi$-hemicontractive if $F(T)=\{x \in D(T): T x=x\} \neq \emptyset$ and if there exists a strictly increasing function $\phi:[0, \infty) \rightarrow[0, \infty)$ with $\phi(0)=0$ such that for any given $x \in D(T)$ and $q \in F(T)$ there exists $j(x-q) \in J(x-q)$ satisfying

$$
\langle T x-q, j(x-q)\rangle \leq\|x-q\|^{2}-\phi(\|x-q\|)\|x-q\| .
$$

In [8], Chidume and Osilike proved that the class of $\phi$-strongly pseudocontractive operators with a nonempty fixed point set is a proper subset of the class of $\phi$-hemicontractive operators. In [3], Chidume obtained that if $K$ is a nonempty closed convex bounded subset of $X$ and $T: K \rightarrow K$ is a Lipschitz strongly pseudocontractive operator, then the Mann iteration sequence converges strongly to the fixed point of $T$. In [10], Deng generalized the result to the Ishikawa iteration sequence. Tan and Xu [18] extended the results of Chidume [3] and Deng [10] to real $q$-uniformly smooth Banach spaces, where $1<q<2$. Osilike [15] improved the results of Chidume [3], Deng [10], Tan and Xu [18] to both real $q$-uniformly smooth Banach spaces, where $q>1$ and $\phi$ hemicontractive operator. Recently, Osilike [16] generalized the above results to a real Banach space, and Liu and Kang [13], [14] extended Osilike's results to the Ishikawa iteration sequence with errors in a real Banach space.

In this paper our purpose is to show that the three-step iteration sequences with errors converge strongly to the unique fixed point of $T$ if $T: K \rightarrow K$ is a Lipschitz $\phi$-hemicontractive operator or $T: K \rightarrow K$ is a uniformly continuous $\phi$-hemicontractive operator, where $X$ is a real Banach space and $K$ is a nonempty closed convex subset of $X$. Our results extend, improve and unify the results in Chang [1], Chang et al. [2], Chidume [3]-[7], Chidume and Osilike [9], Deng [10], Liu and Kang [13], [14], Osilike [15], [16], Tan and Xu [17].

The following lemmas are of importance in the proofs of our results.

LEMMA 1.1. [13] Suppose that $\phi:[0, \infty) \rightarrow[0, \infty)$ is a strictly increasing function with $\phi(0)=0$. If $\left\{r_{n}\right\}_{n=0}^{\infty},\left\{s_{n}\right\}_{n=0}^{\infty},\left\{k_{n}\right\}_{n=0}^{\infty}$ and 
$\left\{t_{n}\right\}_{n=0}^{\infty}$ are sequence of nonnegative numbers satisfying the following conditions:

$$
\begin{gathered}
\sum_{n=0}^{\infty} k_{n}<\infty, \quad \sum_{n=0}^{\infty} t_{n}<\infty, \quad \sum_{n=0}^{\infty} s_{n}=\infty \\
r_{n+1} \leq\left(1+k_{n}\right) r_{n}-s_{n} r_{n} \frac{\phi\left(r_{n+1}\right)}{1+\phi\left(r_{n+1}\right)+r_{n+1}}+t_{n}, \quad n \geq 0,
\end{gathered}
$$

then $\lim _{n \rightarrow \infty} r_{n}=0$.

LEMMA 1.2. [12] Let $\left\{\alpha_{n}\right\}_{n=0}^{\infty},\{\beta\}_{n=0}^{\infty}$ and $\left\{\gamma_{n}\right\}_{n=0}^{\infty}$ be three nonnegative real sequences satisfying the inequality

$$
\alpha_{n+1} \leq\left(1-\omega_{n}\right) \alpha_{n}+\beta_{n} \omega_{n}+\gamma_{n} \text { for } n \geq 0,
$$

where $\left\{\omega_{n}\right\}_{n=0}^{\infty} \subset[0,1], \sum_{n=0}^{\infty} \omega_{n}=\infty, \lim _{n \rightarrow \infty} \beta_{n}=0$ and $\sum_{n=0}^{\infty} \gamma_{n}<$ $\infty$. Then $\lim _{n \rightarrow \infty} \alpha_{n}=0$.

\section{Main results}

Theorem 2.1. Let $X$ be a real Banach space, $K$ be a nonempty closed convex subset of $X$ and $T: K \rightarrow K$ be a Lipschitz $\phi$-hemicontractive operator with the Lipschitz constant $L \geq 1$. For any $x_{0}, u_{0}, v_{0}, w_{0} \in$ $K$, the three-step iteration sequence with errors $\left\{x_{n}\right\}_{n=0}^{\infty}$ defined by

$$
\begin{aligned}
& z_{n}=a_{n}^{\prime \prime} x_{n}+b_{n}^{\prime \prime} T x_{n}+c_{n}^{\prime \prime} w_{n}, \\
& y_{n}=a_{n}^{\prime} x_{n}+b_{n}^{\prime} T z_{n}+c_{n}^{\prime} v_{n}, \\
& x_{n+1}=a_{n} x_{n}+b_{n} T y_{n}+c_{n} u_{n}, \quad n \geq 0,
\end{aligned}
$$

where $\left\{u_{n}\right\}_{n=0}^{\infty},\left\{v_{n}\right\}_{n=0}^{\infty}$ and $\left\{w_{n}\right\}_{n=0}^{\infty}$ are arbitrary bounded sequences in $K,\left\{a_{n}\right\},\left\{b_{n}\right\},\left\{c_{n}\right\},\left\{a_{n}^{\prime}\right\},\left\{b_{n}^{\prime}\right\},\left\{c_{n}^{\prime}\right\},\left\{a_{n}^{\prime \prime}\right\},\left\{b_{n}^{\prime \prime}\right\}$ and $\left\{c_{n}^{\prime \prime}\right\}$ are real sequences in $[0,1]$ satisfying the following conditions:

$$
\begin{gathered}
a_{n}+b_{n}+c_{n}=a_{n}^{\prime}+b_{n}^{\prime}+c_{n}^{\prime}=a_{n}^{\prime \prime}+b_{n}^{\prime \prime}+c_{n}^{\prime \prime}=1, \quad n \geq 0 \\
\sum_{n=0}^{\infty} c_{n}<\infty, \quad \sum_{n=0}^{\infty} b_{n} b_{n}^{\prime}<\infty, \quad \sum_{n=0}^{\infty} b_{n} c_{n}^{\prime}<\infty, \quad \sum_{n=0}^{\infty} b_{n}^{2}<\infty \\
\sum_{n=0}^{\infty} b_{n}=\infty
\end{gathered}
$$

Then the sequence $\left\{x_{n}\right\}_{n=0}^{\infty}$ converges strongly to the unique fixed point of $T$. 
Proof. Since $T$ is a $\phi$-hemicontractive operator, $F(T)$ is a nonempty set. We claim that $F(T)$ is a singleton. Otherwise, for any different $p, q \in F(T)$ we conclude that

$$
\begin{aligned}
\|p-q\|^{2} & =\langle T p-q, j(p-q)\rangle \\
& \leq\|p-q\|^{2}-\phi(\|p-q\|)\|p-q\| \\
& <\|p-q\|^{2},
\end{aligned}
$$

which is a contradiction and hence $F(T)$ is a singleton. Let $F(T)=\{q\}$. Since $T$ is a $\phi$-hemicontractive operator, we know that for $x \in K$

$$
\begin{aligned}
\langle(I-T) x-(I-T) q, j(x-q)\rangle & \geq \phi(\|x-q\|)\|x-q\| \\
& \geq A(x, q)\|x-q\|^{2},
\end{aligned}
$$

where $A(x, q)=\frac{\phi(\|x-q\|)}{1+\phi(\|x-q\|)+\|x-q\|} \in[0,1)$. Lemma 1.1 of Kato [11] ensures that for any $x \in K$ and $r>0$

(2.5) $\|x-q\| \leq\|x-q+r[(I-T-A(x, q)) x-(I-T-A(x, q)) q]\|$.

Put $d_{n}=b_{n}+c_{n}, d_{n}^{\prime}=b_{n}^{\prime}+c_{n}^{\prime}$ and $d_{n}^{\prime \prime}=b_{n}^{\prime \prime}+c_{n}^{\prime \prime}$ for $n \geq 0$. According to (2.1) we have that

$$
\begin{aligned}
x_{n}= & x_{n+1}+d_{n} x_{n}-d_{n} T y_{n}+c_{n}\left(T y_{n}-u_{n}\right) \\
= & \left(1+d_{n}\right) x_{n+1}+d_{n}\left(I-T-A\left(x_{n+1}, q\right)\right) x_{n+1} \\
& -\left(1-A\left(x_{n+1}, q\right)\right) d_{n} x_{n}+\left(2-A\left(x_{n+1}, q\right)\right) d_{n}^{2}\left(x_{n}-T y_{n}\right) \\
& +d_{n}\left(T x_{n+1}-T y_{n}\right)+c_{n}\left[1+\left(2-A\left(x_{n+1}, q\right)\right) d_{n}\right] \\
& \times\left(T y_{n}-u_{n}\right)
\end{aligned}
$$

and

$$
q=\left(1+d_{n}\right) q+d_{n}\left(I-T-A\left(x_{n+1}, q\right)\right) q-\left(1-A\left(x_{n+1}, q\right)\right) d_{n} q
$$

for $n \geq 0$. It follows from (2.5)-(2.7) that

$$
\begin{aligned}
& \left\|x_{n}-q\right\| \\
\geq & \left(1+d_{n}\right) \| x_{n+1}-q+\frac{d_{n}}{1+d_{n}}\left[\left(I-T-A\left(x_{n+1}, q\right)\right) x_{n+1}\right. \\
& \left.-\left(I-T-A\left(x_{n+1}, q\right)\right) q\right]\left\|-d_{n}\left(1-A\left(x_{n+1}, q\right)\right)\right\| x_{n}-q \| \\
& -\left(2-A\left(x_{n+1}, q\right)\right) d_{n}^{2}\left\|x_{n}-T y_{n}\right\|-d_{n}\left\|T x_{n+1}-T y_{n}\right\| \\
& -c_{n}\left[1+\left(2-A\left(x_{n+1}, q\right)\right) d_{n}\right]\left\|T y_{n}-u_{n}\right\| \\
\geq & \left(1+d_{n}\right)\left\|x_{n+1}-q\right\|-d_{n}\left(1-A\left(x_{n+1}, q\right)\right)\left\|x_{n}-q\right\| \\
& -\left(2-A\left(x_{n+1}, q\right)\right) d_{n}^{2}\left\|x_{n}-T y_{n}\right\|-d_{n}\left\|T x_{n+1}-T y_{n}\right\| \\
& -c_{n}\left[1+\left(2-A\left(x_{n+1}, q\right)\right) d_{n}\right]\left\|T y_{n}-u_{n}\right\|,
\end{aligned}
$$


which implies that

$$
\begin{aligned}
& \left\|x_{n+1}-q\right\| \\
\leq & \frac{1+\left(1-A\left(x_{n+1}, q\right)\right) d_{n}}{1+d_{n}}\left\|x_{n}-q\right\| \\
& +\left(2-A\left(x_{n+1}, q\right)\right) d_{n}^{2}\left\|x_{n}-T y_{n}\right\|+d_{n}\left\|T x_{n+1}-T y_{n}\right\| \\
& +c_{n}\left[1+\left(2-A\left(x_{n+1}, q\right)\right) d_{n}\right]\left\|T y_{n}-u_{n}\right\| \\
\leq & \left(1-A\left(x_{n+1}, q\right) d_{n}+d_{n}^{2}\right)\left\|x_{n}-q\right\|+2 d_{n}^{2}\left\|x_{n}-T y_{n}\right\| \\
& +d_{n}\left\|T x_{n+1}-T y_{n}\right\|+c_{n}\left(1+2 d_{n}\right)\left\|T y_{n}-u_{n}\right\|
\end{aligned}
$$

for $n \geq 0$. Set $B=\sup \left\{\left\|u_{n}-q\right\|,\left\|v_{n}-q\right\|,\left\|w_{n}-q\right\|: n \geq 0\right\}$. By virtue of $(2.1)$ we get that

$$
\begin{aligned}
& \left\|z_{n}-q\right\| \\
\leq & \left(1-d_{n}^{\prime \prime}\right)\left\|x_{n}-q\right\|+d_{n}^{\prime \prime} L\left\|x_{n}-q\right\| \\
& +c_{n}^{\prime \prime}\left(\left\|w_{n}-q\right\|+L\left\|x_{n}-q\right\|\right) \\
\leq & \left(1-d_{n}^{\prime \prime}+d_{n}^{\prime \prime} L+L c_{n}^{\prime \prime}\right)\left\|x_{n}-q\right\|+c_{n}^{\prime \prime}\left\|w_{n}-q\right\| \\
\leq & 2 L\left\|x_{n}-q\right\|+c_{n}^{\prime \prime} B
\end{aligned}
$$

for $n \geq 0$. In view of (2.1) and (2.9) we obtain that

$$
\begin{aligned}
& \left\|y_{n}-q\right\| \\
\leq & \left(1-d_{n}^{\prime}\right)\left\|x_{n}-q\right\|+d_{n}^{\prime} L\left\|z_{n}-q\right\| \\
& +c_{n}^{\prime}\left(\left\|v_{n}-q\right\|+L\left\|z_{n}-q\right\|\right) \\
\leq & {\left[\left(1-d_{n}^{\prime}\right)+2 L^{2}\left(d_{n}^{\prime}+c_{n}^{\prime}\right)\right]\left\|x_{n}-q\right\|+L\left(d_{n}^{\prime}+c_{n}^{\prime}\right) c_{n}^{\prime \prime} B+c_{n}^{\prime} B } \\
\leq & {\left[1+2 L^{2}\left(d_{n}^{\prime}+c_{n}^{\prime}\right)\right]\left\|x_{n}-q\right\|+L\left(d_{n}^{\prime}+c_{n}^{\prime}\right) c_{n}^{\prime \prime} B+c_{n}^{\prime} B }
\end{aligned}
$$

for $n \geq 0$. According to (2.1), (2.9) and (2.10) we conclude that

$$
\begin{aligned}
& \left\|x_{n}-T y_{n}\right\| \\
\leq & \left\|x_{n}-q\right\|+\left\|T y_{n}-q\right\| \\
\leq & \left\|x_{n}-q\right\|+L\left\|y_{n}-q\right\| \\
\leq & {\left[1+L+2 L^{3}\left(d_{n}^{\prime}+c_{n}^{\prime}\right)\right]\left\|x_{n}-q\right\|+\left[L^{2}\left(d_{n}^{\prime}+c_{n}^{\prime}\right) c_{n}^{\prime \prime}+L c_{n}^{\prime}\right] B }
\end{aligned}
$$

and

$$
\begin{aligned}
& \left\|x_{n}-y_{n}\right\| \\
\leq & d_{n}^{\prime}\left\|x_{n}-T z_{n}\right\|+c_{n}^{\prime}\left\|T z_{n}-v_{n}\right\| \\
\leq & {\left[d_{n}^{\prime}+2 L^{2}\left(d_{n}^{\prime}+c_{n}^{\prime}\right)\right]\left\|x_{n}-q\right\|+\left[L\left(d_{n}^{\prime}+c_{n}^{\prime}\right) c_{n}^{\prime \prime}+c_{n}^{\prime}\right] B }
\end{aligned}
$$


for $n \geq 0$. It follows from (2.1) and (2.9)-(2.12) that

$$
\begin{aligned}
& \left\|T x_{n+1}-T y_{n}\right\| \\
\leq & L\left(1-d_{n}\right)\left\|x_{n}-y_{n}\right\|+L d_{n}\left\|T y_{n}-y_{n}\right\|+L c_{n}\left\|T y_{n}-u_{n}\right\| \\
\leq & L\left\|x_{n}-y_{n}\right\|+\left(L^{2} d_{n}+L^{2} c_{n}+L d_{n}\right)\left\|y_{n}-q\right\|+L c_{n} B \\
\leq & {\left[L d_{n}^{\prime}+2 L^{3}\left(d_{n}^{\prime}+c_{n}^{\prime}\right)+L d_{n}+L^{2}\left(d_{n}+c_{n}\right)\right.} \\
& \left.+2 L^{3} d_{n}\left(d_{n}^{\prime}+c_{n}^{\prime}\right)+2 L^{4}\left(d_{n}+c_{n}\right)\left(d_{n}^{\prime}+c_{n}^{\prime}\right)\right]\left\|x_{n}-q\right\| \\
& +\left[L^{2}\left(d_{n}^{\prime}+c_{n}^{\prime}\right) c_{n}^{\prime \prime}+L^{3}\left(d_{n}+c_{n}\right)\left(d_{n}^{\prime}+c_{n}^{\prime}\right) c_{n}^{\prime \prime}\right. \\
& +L^{2}\left(d_{n}+c_{n}\right) c_{n}^{\prime}+L^{2} d_{n}\left(d_{n}^{\prime}+c_{n}^{\prime}\right) c_{n}^{\prime \prime}+L d_{n} c_{n}^{\prime} \\
& \left.+L c_{n}+L c_{n}^{\prime}\right] B
\end{aligned}
$$

for $n \geq 0$. Substituting (2.11) and (2.13) into (2.8), we obtain that

$$
\begin{aligned}
& \left\|x_{n+1}-q\right\| \\
\leq & {\left[1-A\left(x_{n+1}, q\right) d_{n}\right]\left\|x_{n}-q\right\|+\left[3 d_{n}^{2}+2 L d_{n}^{2}\right.} \\
& +4 L^{3} d_{n}^{2}\left(d_{n}^{\prime}+c_{n}^{\prime}\right)+L d_{n} d_{n}^{\prime}+2 L^{3} d_{n}\left(d_{n}^{\prime}+c_{n}^{\prime}\right)+L d_{n}^{2} \\
& +L^{2} d_{n}\left(d_{n}+c_{n}\right)+2 L^{4} d_{n}\left(d_{n}+c_{n}\right)\left(d_{n}^{\prime}+c_{n}^{\prime}\right) \\
& \left.+L c_{n}\left(1+2 d_{n}\right)+2 L^{3} c_{n}\left(1+2 d_{n}\right)\left(d_{n}^{\prime}+c_{n}^{\prime}\right)\right]\left\|x_{n}-q\right\| \\
& +\left[2 L^{2} d_{n}^{2} c_{n}^{\prime \prime}\left(d_{n}^{\prime}+c_{n}^{\prime}\right)+2 L d_{n}^{2} c_{n}^{\prime}+L^{2} d_{n} c_{n}^{\prime \prime}\left(d_{n}^{\prime}+c_{n}^{\prime}\right)\right. \\
& +L^{3} d_{n} c_{n}^{\prime \prime}\left(d_{n}+c_{n}\right)\left(d_{n}^{\prime}+c_{n}^{\prime}\right)+L^{2} d_{n} c_{n}^{\prime}\left(d_{n}+c_{n}\right) \\
& +L^{2} d_{n}^{2} c_{n}^{\prime \prime}\left(d_{n}^{\prime}+c_{n}^{\prime}\right)+L d_{n}^{2} c_{n}^{\prime}+L d_{n} c_{n}+L d_{n} c_{n}^{\prime} \\
& +L^{2} c_{n} c_{n}^{\prime \prime}\left(1+2 d_{n}\right)\left(d_{n}^{\prime}+c_{n}^{\prime}\right)+L c_{n} c_{n}^{\prime}\left(1+2 d_{n}\right) \\
& \left.+c_{n}\left(1+2 d_{n}\right)\right] B \\
\leq & {\left[1+M_{1}\left(d_{n}^{2}+d_{n} d_{n}^{\prime}+c_{n}\right)\right]\left\|x_{n}-q\right\|-A\left(x_{n+1}, q\right) d_{n}\left\|x_{n}-q\right\| } \\
& +M_{2} B\left(d_{n}^{2}+c_{n}^{\prime} d_{n}+c_{n}+d_{n} d_{n}^{\prime}\right)
\end{aligned}
$$

for $n \geq 0$ and some positive constants $M_{1}$ and $M_{2}$. Put

$$
\begin{aligned}
& r_{n}=\left\|x_{n}-q\right\|, \quad s_{n}=d_{n}, \quad k_{n}=M_{1}\left(d_{n}^{2}+d_{n}^{\prime} d_{n}+c_{n}\right), \\
& t_{n}=M_{2} B\left(d_{n}^{2}+c_{n}^{\prime} d_{n}+c_{n}+d_{n} d_{n}^{\prime}\right) \quad \text { for } n \geq 0 .
\end{aligned}
$$

It follows from (2.3), (2.4), (2.14) and Lemma 1.1 that $r_{n} \rightarrow 0$ as $n \rightarrow \infty$. This completes the proof. 
Theorem 2.2. Suppose that $X$ is a real Banach space, $K$ is a nonempty convex subset of $X$ and $T: K \rightarrow K$ is a uniformly continuous $\phi$-hemicontractive operator. For any $x_{0}, u_{0}, v_{0}, w_{0} \in K$, let $\left\{x_{n}\right\}_{n=0}^{\infty}$ be defined by (2.1), where $\left\{u_{n}\right\}_{n=0}^{\infty},\left\{v_{n}\right\}_{n=0}^{\infty}$ and $\left\{w_{n}\right\}_{n=0}^{\infty}$ are arbitrary bounded sequences in $K,\left\{a_{n}\right\},\left\{b_{n}\right\},\left\{c_{n}\right\},\left\{a_{n}^{\prime}\right\},\left\{b_{n}^{\prime}\right\},\left\{c_{n}^{\prime}\right\},\left\{a_{n}^{\prime \prime}\right\},\left\{b_{n}^{\prime \prime}\right\}$ and $\left\{c_{n}^{\prime \prime}\right\}$ are real sequences in $[0,1]$ satisfying $(2.2)$ and the following conditions

$$
\begin{gathered}
b_{n}+c_{n} \in(0,1), \quad n \geq 0 \\
\lim _{n \rightarrow \infty} b_{n}=\lim _{n \rightarrow \infty} b_{n}^{\prime}=\lim _{n \rightarrow \infty} c_{n}^{\prime}=\lim _{n \rightarrow \infty} \frac{c_{n}}{b_{n}+c_{n}}=0 \\
\sum_{n=0}^{\infty} b_{n}=+\infty .
\end{gathered}
$$

If $R(T)$ is bounded, then the sequence $\left\{x_{n}\right\}_{n=0}^{\infty}$ converges strongly to the unique fixed point of $T$.

Proof. As in the proof of Theorem 2.1, we conclude that $F(T)$ is a singleton. Put $F(T)=\{q\}$. Thus for $x \in K$,

$$
\begin{aligned}
\langle(I-T) x-(I-T) q, j(x-q)\rangle & \geq \phi(\|x-q\|)\|x-q\| \\
& \geq A(x, q)\|x-q\|^{2},
\end{aligned}
$$

where $A(x, q)=\frac{\phi(\|x-q\|)}{1+\phi(\|x-q\|)+\|x-q\|} \in[0,1)$. It follows from Lemma 1.1 of Kato [11] that

$$
\|x-q\| \leq\|x-q+r[(I-T-A(x, q)) x-(I-T-A(x, q)) q]\|
$$

for $x \in K$ and $r>0$. Set $d_{n}=b_{n}+c_{n}, d_{n}^{\prime}=b_{n}^{\prime}+c_{n}^{\prime}$ and $d_{n}^{\prime \prime}=b_{n}^{\prime \prime}+c_{n}^{\prime \prime}$ for $n \geq 0$ and

$$
\begin{aligned}
D=\sup \left\{\left\|T x_{n}-q\right\|,\left\|T y_{n}-q\right\|,\left\|T z_{n}-q\right\|,\right. \\
\left.\left\|u_{n}-q\right\|,\left\|v_{n}-q\right\|,\left\|w_{n}-q\right\|: n \geq 0\right\} .
\end{aligned}
$$

Since $R(T)$ and $\left\{u_{n}\right\},\left\{v_{n}\right\}$ and $\left\{w_{n}\right\}$ are bounded, it follows that $D<$ $\infty$. According to (2.1) and (2.18), we deduce that

$$
\sup \left\{\left\|x_{n}-q\right\|,\left\|y_{n}-q\right\|: n \geq 0\right\} \leq D .
$$


In view of (2.1) we infer that

$$
\begin{aligned}
& \left(1-d_{n}\right) x_{n} \\
= & x_{n+1}-d_{n} T y_{n}-c_{n}\left(u_{n}-T y_{n}\right) \\
= & {\left[1-\left(1-A\left(x_{n+1}, q\right)\right) d_{n}\right] x_{n+1}+d_{n}\left(I-T-A\left(x_{n+1}, q\right)\right) x_{n+1} } \\
& +d_{n}\left(T x_{n+1}-T y_{n}\right)-c_{n}\left(u_{n}-T y_{n}\right)
\end{aligned}
$$

and

(2.21) $\left(1-d_{n}\right) q=\left[1-\left(1-A\left(x_{n+1}, q\right)\right) d_{n}\right] q+d_{n}\left(I-T-A\left(x_{n+1}, q\right)\right) q$ for $n \geq 0$. It follows from (2.2), (2.5), (2.20) and (2.21) that

$$
\begin{aligned}
& \left(1-d_{n}\right)\left\|x_{n}-q\right\| \\
\geq & {\left[1-\left(1-A\left(x_{n+1}, q\right)\right) d_{n}\right] \| x_{n+1}-q+\frac{d_{n}}{1-\left(1-A\left(x_{n+1}, q\right)\right) d_{n}} } \\
& \times\left[\left(I-T-A\left(x_{n+1}, q\right)\right) x_{n+1}-\left(I-T-A\left(x_{n+1}, q\right)\right) q\right] \| \\
& -d_{n}\left\|T x_{n+1}-T y_{n}\right\|-c_{n}\left\|u_{n}-T y_{n}\right\| \\
\geq & {\left[1-\left(1-A\left(x_{n+1}, q\right)\right) d_{n}\right]\left\|x_{n+1}-q\right\|-d_{n}\left\|T x_{n+1}-T y_{n}\right\|-2 D c_{n}, }
\end{aligned}
$$

which implies that

$$
\begin{aligned}
& \left\|x_{n+1}-q\right\| \\
\leq & \frac{1-d_{n}}{1-\left(1-A\left(x_{n+1}, q\right)\right) d_{n}}\left\|x_{n}-q\right\| \\
& +\frac{d_{n}}{1-\left(1-\left(A x_{n+1}, q\right)\right) d_{n}}\left\|T x_{n+1}-T y_{n}\right\| \\
& +\frac{2 D c_{n}}{1-\left(1-A\left(x_{n+1}, q\right)\right) d_{n}} \\
\leq & \left(1-A\left(x_{n+1}, q\right) d_{n}\right)\left\|x_{n}-q\right\|+M d_{n}\left\|T x_{n+1}-T y_{n}\right\|+M c_{n}
\end{aligned}
$$

for $n \geq 0$, where $M$ is some constant. According to (2.1), (2.2), (2.15) and (2.16), we get that

$$
\begin{aligned}
& \left\|x_{n+1}-y_{n}\right\| \\
\leq & \left\|x_{n+1}-x_{n}\right\|+\left\|y_{n}-x_{n}\right\| \\
\leq & b_{n}\left\|T y_{n}-x_{n}\right\|+c_{n}\left\|u_{n}-x_{n}\right\|+b_{n}^{\prime}\left\|T z_{n}-x_{n}\right\|+c_{n}^{\prime}\left\|v_{n}-x_{n}\right\| \\
\leq & 2 D\left(d_{n}^{\prime}+d_{n}\right) \\
\rightarrow & 0
\end{aligned}
$$


as $n \rightarrow \infty$. The uniform continuity of $T$ ensures that

$$
\left\|T x_{n+1}-T y_{n}\right\| \rightarrow 0 \text { as } n \rightarrow \infty .
$$

Set $\inf \left\{A\left(x_{n+1}, q\right): n \geq 0\right\}=r$. We assert that $r=0$. If not, then $r>0$. In view of $(2.22)$, we have that

$$
\left\|x_{n+1}-q\right\| \leq\left(1-r d_{n}\right)\left\|x_{n}-q\right\|+M d_{n}\left\|T x_{n+1}-T y_{n}\right\|+M c_{n}
$$

for all $n \geq 0$. Let $\alpha_{n}=\left\|x_{n}-q\right\|, \omega_{n}=r d_{n}, \beta_{n}=M r^{-1} \| T x_{n+1}-$ $T y_{n} \|+M r^{-1} c_{n} d_{n}^{-1}$ and $\gamma_{n}=0$ for $n \geq 0$. By (2.16), (2.17), (2.23), (2.24) and Lemma 1.2 we conclude that $\left\|x_{n}-q\right\| \rightarrow 0$ as $n \rightarrow \infty$, which means that $r=0$, which is a contradiction. Therefore $r=0$ and there exists a subsequence $\left\{\left\|x_{n_{i}+1}-q\right\|\right\}_{i=1}^{\infty}$ of $\left\{\left\|x_{n+1}-q\right\|\right\}_{n=0}^{\infty}$ satisfying

$$
\left\|x_{n_{i}+1}-q\right\| \rightarrow 0 \quad \text { as } i \rightarrow \infty
$$

Employing (2.16), (2.23) and (2.25) we conclude that given $\varepsilon>0$, there exists a positive integer $m$ satisfying

$$
\left\|x_{n_{m}+1}-q\right\|<\varepsilon
$$

and

$$
M\left\|T x_{n+1}-T y_{n}\right\|+M \frac{c_{n}}{d_{n}}<\min \left\{\frac{1}{2} \varepsilon, \frac{\phi(\varepsilon) \varepsilon}{1+\phi\left(\frac{3}{2} \varepsilon\right)+\frac{3}{2} \varepsilon}\right\}
$$

for $n \geq N$. Now we show that

$$
\left\|x_{n_{m}+j}-q\right\| \leq \varepsilon \text { for } j \geq 1 .
$$

Clearly (2.26) means that (2.28) holds for $j=1$. Assume that (2.28) holds for $j=k$. If $\left\|x_{n_{m}+k+1}-q\right\|>\varepsilon$, we obtain that by (2.22) and (2.27)

$$
\begin{aligned}
& \left\|x_{n_{m}+k+1}-q\right\| \\
\leq & \left\|x_{n_{m}+k}-q\right\|+M d_{n_{m}+k}\left\|T x_{n_{m}+k+1}-T y_{n_{m}+k}\right\|+M c_{n_{m}+k} \\
(2.29) \leq & \varepsilon+\min \left\{\frac{1}{2} \varepsilon, \frac{\phi(\varepsilon) \varepsilon}{1+\phi\left(\frac{3}{2} \varepsilon\right)+\frac{3}{2} \varepsilon}\right\} d_{n_{m}+k} \\
\leq & \frac{3}{2} \varepsilon .
\end{aligned}
$$


Note that $\phi\left(\left\|x_{n_{m}+k+1}-q\right\|\right)>\phi(\varepsilon)$. It follows from (2.29) that

$$
A\left(x_{n_{m}+k+1}, q\right) \geq \frac{\phi(\varepsilon)}{1+\phi\left(\frac{3}{2} \varepsilon\right)+\frac{3}{2} \varepsilon} .
$$

By virtue of $(2.22),(2.27)$ and $(2.30)$, we obtain the following estimates:

$$
\begin{aligned}
& \left\|x_{n_{m}+k+1}-q\right\| \\
\leq & \left(1-\frac{\phi(\varepsilon)}{1+\phi\left(\frac{3}{2} \varepsilon\right)+\frac{3}{2} \varepsilon} d_{n_{m}+k}\right)\left\|x_{n_{m}+k}-q\right\| \\
& +M d_{n_{m}+k}\left\|T x_{x_{m}+k+1}-T y_{n_{m}+k}\right\|+M c_{n_{m}+k} \\
\leq & \left(1-\frac{\phi(\varepsilon)}{1+\phi\left(\frac{3}{2} \varepsilon\right)+\frac{3}{2} \varepsilon} d_{n_{m}+k}\right) \varepsilon \\
& +\min \left\{\frac{1}{2} \varepsilon, \frac{\phi(\varepsilon) \varepsilon}{1+\phi\left(\frac{3}{2} \varepsilon\right)+\frac{3}{2} \varepsilon}\right\} d_{n_{m}+k} \\
\leq & \varepsilon .
\end{aligned}
$$

That is,

$$
\varepsilon<\left\|x_{n_{m}+k+1}-q\right\| \leq \varepsilon,
$$

which is a contradiction. Hence $\left\|x_{n_{m}+k+1}-q\right\| \leq \varepsilon$. By induction, (2.28) holds for $j \geq 1$. It follows from (2.28) that $x_{n} \rightarrow q$ as $n \rightarrow \infty$. This completes the proof.

REMARK 2.1. Theorems 2.1 and 2.2 extend and improve Theorem 3.3 of Chang [1], Theorem 3.2 of Chang et al. [2], Theorem of Chidume [3], Theorem 2 of Chidume [4], Theorem 2 of Chidume [5], Theorem 4 of Chidume [6], Theorem 13 of Chidume [7], Theorems 2 and 4 of Chidume and Osilike [9], Theorems 2 and 4 of Deng [10], Theorem 3.3 of Liu and Kang [13], Theorem 3.1 of Liu and Kang [14], Theorem 2 of Osilike [15], Theorem 2 of Osilike [16], Theorems 3.2 and 4.2 of Tan and Xu [17] in the following ways:

(a) that $X$ be either real uniformly smooth Banach space in [1], [2], [5], [6] or real $q$-uniformly smooth Banach space in [10], [15], [17], or real smooth Banach space in [7], is replaced by the more general real Banach space;

(b) that $T$ be strongly psedo-contractive operator in [1]-[7], [9], [10] is replaced by the more general class of $\phi$-hemicontractive operators;

(c) the Mann iteration sequence in [3], [4], [9], [17], the Ishikawa iteration sequence in [1], [2], [5]-[7], [9], [10], [15]-[17] and the Ishikawa 
iteration sequence with errors in [13], [14] are replaced by the more general three-step iteration sequence with errors.

ACKNowledgement. The author thank the referee for his valuable suggestions for the improvement of the paper.

\section{References}

[1] S. S. Chang, Some problems and results in the study of nonlinear analysis, Nonlinear Anal. 30 (1997), 4197-4208.

[2] S. S. Chang, Y. J. Cho, B. S. Lee and S. M. Kang, Iterative approximation of fixed points and solutions for strongly accretive and strongly pseudo-contractive mappings in Banach spaces, J. Math. Anal. Appl. 224 (1998), 149-165.

[3] C. E. Chidume, Iterative approximation of fixed points of Lipschitz strictly pseudocontractive mappings, Proc. Amer. Math. Soc. 99 (1987), 283-288.

[4] _ An iterative process for nonlinear Lipschitzian strongly accretive mappings in $L_{p}$ spaces, J. Math. Anal. Appl. 151 (1990), 453-461.

[5] - Approximation of fixed points of strongly pseudo-contractive mappings, Proc. Amer. Math. Soc. 120 (1994), 545-551.

[6] - Iterative solution of nonlinear equations with strongly accretive operators, J. Math. Anal. Appl. 192 (1995), 502-518.

[7] Iterative solution of nonlinear equations in smooth Banach spaces, Nonlinear Anal. 26 (1996), 1823-1824.

[8] C. E. Chidume and M. O. Osilike, Fixed point iterations for strictly hemicontractive maps in uniformly smooth Banach spaces, Numer. Func. Anal. Optim. 15 (1994), 779-790.

[9] __ Ishikawa iteration process for nonlinear Lipschitz strongly accretive mappings, J. Math. Anal. Appl. 192 (1995), 727-741.

[10] L. Deng, An iterative process for nonlinear Lipschitz and strongly accretive mappings in uniformly convex and uniformly smooth Banach spaces, Acta Appl. Math. 32 (1993), 183-196.

[11] T. Kato, Nonlinear semigroups and evolution equations, J. Math. Soc. Japan 19 (1967), 508-520.

[12] L. S. Liu, Ishikawa and Mann iterative process with errors for nonlinear strongly accretive mappings in Banach spaces, J. Math. Anal. Appl. 194 (1995), 114-125.

[13] Z. Liu and S. M. Kang, Convergence theorems for $\phi$-strongly accretive and $\phi$ hemicontractive operators, J. Math. Anal. Appl. 253 (2001), 35-49.

[14] _ Iterative approximation of fixed points for $\phi$-hemicontractive operators in arbitrary Banach spaces, Acta Sci. Math. (Szeged) 67 (2001), 821-831.

[15] M. O. Osilike, Iterative solution of nonlinear equations of the $\phi$-strongly accretive type, J. Math. Anal. Appl. 200 (1996), 259-271.

[16] ___ Iterative solution of nonlinear $\phi$-strongly accretive operator equations in arbitrary Banach spaces, Nonlinear Anal. 36 (1999), 1-9.

[17] K. K. Tan and H. K. Xu, Iterative solutions to nonlinear equations of strongly accretive operators in Banach spaces, J. Math. Anal. Appl. 178 (1993), 9-21. 
[18] ___ Approximating fixed points of nonexpansive mappings by the Ishikawa iteration process, J. Math. Anal. Appl. 178 (1993), 301-308.

Zeqing Liu and Zhefu An

Department of Mathematics

Liaoning Normal University

P. O. Box 200, Dalian

Liaoning 116029, P. R. China

E-mail: zeqingliu@sina.com.cn

Yanjuan Li

Shenyang University

Shenyang, Liaoning 110044, P. R. China

Shin Min Kang

Department of Mathematics and RINS

Gyeongsang National University

Chinju 660-701, Korea

E-mail: smkang@nongae.gsnu.ac.kr 